2014-03-18

\title{
Energy productivity and efficiency of wheat farming in Bangladesh
}

\author{
Rahman, Sanzidur
}

http://hdl.handle.net/10026.1/3997

10.1016/j.energy.2013.12.070

Energy

Elsevier

All content in PEARL is protected by copyright law. Author manuscripts are made available in accordance with publisher policies. Please cite only the published version using the details provided on the item record or document. In the absence of an open licence (e.g. Creative Commons), permissions for further reuse of content should be sought from the publisher or author. 
EGY-D-12-02143.R2

(Incorporating final comments of referee\#2 and \#3 and the editor)

EnERgy Productivity ANd EFFiciency OF WHEAT FARMing IN BANGLAdESH

\section{Sanzidur Rahman}

School of Geography, Earth and Environmental Sciences, University of Plymouth, UK

E-mail: $\underline{\text { srahman@plymouth.ac.uk }}$

\section{Kamrul Hasan}

Planning and Evaluation Division, Bangladesh Agricultural Research Institute (BARI), Gazipur - 1701, Bangladesh, E-mail: khasan41@yahoo.com

\section{$\underline{\text { Address for correspondence }}$}

Dr. Sanzidur Rahman

Associate Professor in Rural Development

School of Geography, Earth and Environmental Sciences

University of Plymouth

Drake Circus

Plymouth, PL4 8AA, United Kingdom

Phone: $+44-1752-585911$

Fax: $+44-1752-585998$

E-mail: $\underline{\text { srahman@plymouth.ac.uk }}$

June 2013 


\title{
Energy Productivity and EfFiciency of Wheat Farming in BangladeSh
}

\begin{abstract}
Wheat is the second most important cereal crop in Bangladesh and production is highly sensitive to variations in the environment. We estimate productivity and energy efficiency of wheat farming in Bangladesh by applying a stochastic production frontier approach while accounting for the environmental constraints affecting production. Wheat farming is energy efficient with a net energy balance of 20,596 MJ per ha and energy ratio of 2.34 . Environmental constraints such as a combination of unsuitable land, weed and pest attack, bad weather, planting delay and infertile soils significantly reduce wheat production and its energy efficiency. Environmental constraints account for a mean energy efficiency of 3 percentage points. Mean technical efficiency is $88 \%$ thereby indicating that elimination of inefficiencies can increase wheat energy output by 12\%. Farmers' education, access to agricultural information and training in wheat production significantly improves efficiency, whereas events such as a delay in planting and first fertilization significantly reduce it. Policy recommendations include development of varieties that are resistant to environmental constraints and suitable for marginal areas; improvement of wheat farming practices; and investments in education and training of farmers as well as dissemination of information.
\end{abstract}

Keywords: Energy productivity, Energy efficiency, Environmental constraints, Stochastic production frontier, Wheat, Bangladesh.

\section{Introduction}

Energy is essential for development in Bangladesh as any other countries of the world. It is also one of the most critical as well as deficient resource in Bangladesh affecting all spheres of life including agricultural development. Effective use of available energy resources is crucial for an economy to develop and become competitive in the world market [1]. In agriculture, energy is used in various forms (e.g., directly as farm machinery powered by electricity and/or diesel fuel, 
human and draft animal power, and indirectly through inorganic fertilizers and pesticides), and therefore, its effective utilization is important.

Commercial energy use in Bangladesh agriculture has been modest but is increasing rapidly in recent years. For example, Bain [2] noted that energy intensity (i.e., commercial energy/GDP ratio) in Bangladesh agriculture has increased steadily from 0.36 in 1977 to 1.87 in 2000. More recently, Khosruzzaman et al. [3] noted that energy intensity in the agricultural sector has increased from only 1.78 in 2000 to a high level of 11.31 in 2008 , implying that the sector is becoming energy intensive, thereby, adding further a crisis to the existing problem of acute energy deficiency in the economy. The main reason for rapid increase in energy use in agriculture can be attributed to widespread diffusion of the 'Green Revolution' technology which is composed of high yielding varieties of seeds, chemical fertilizers, pesticides and supplementary irrigation and drainage. Although the use of commercial energy in agriculture is not a bad sign but the phenomenon is creating additional strain on the already deficient resource.

Wheat is one of the main cereal crops that meet major food demands of the world including Bangladesh. Wheat has contributed more calories and protein to the world's diet than any other food crops [4]. Although rice has been the dominant staple in Bangladeshi diet, import of wheat since the early 1970s to combat food deficit has resulted in a change of diet in recent years. Wheat area now ranks second after rice area in production. In fact, the total production of wheat has increased nearly six folds from only 110.0 thousand tons in 1972 to 735.5 thousand tons in 2006 [5].

According to the Bangladesh Soil Survey report, wheat can be planted in 3.1 million ha of land [5] which is equivalent to $42.3 \%$ of net cultivated area or $25.5 \%$ of gross cropped area of the country in 2005 [6]. Also, profit generated from wheat is much higher in regions with no irrigation and those unsuited to Boro rice (dry winter season) cultivation and represents the most efficient use of scarce resources when costed in terms of economic prices [7]. At face value, wheat can easily replace the dominant rice based staple in Bangladeshi diet 
as it uses significantly less amount of water in its production process, which in turn is also becoming a scarce resource. For example, rice consumes $19121 / \mathrm{kg}$ as compared to wheat at 900 1/kg [8]. However, given unprecedented rise of the demand for energy in Bangladesh agriculture, it is not known whether wheat production is a net energy user or producer. Bangladesh should aim to adopt production technologies that produce more energy as outputs than it uses as inputs at least and at the same time contributes to the nutritional requirement of its population. In fact, the major thrust of the National Food Policy of Bangladesh (20082015 ) is to link agricultural productivity and diversification with improvements of nutritional standards through a three-pronged approach: (a) raising productivity and efficiency of production for major cereals, (b) diversifying into non-cereal crops, including pulses, oilseeds and higher value horticultural crops (e.g., fruits, vegetables, spices); and (c) expanding fishery, livestock and poultry production [9]. This is because although rice has contributed to achieve self-sufficiency in foodgrain in Bangladesh, it was made possible through expansion of irrigation, use of inorganic fertilizers and modern varieties. However, there is a realization that rice cannot be expected to continue to perform as it did in the past [9]. The policy document also emphasized that food consumption trends in Bangladesh are not encouraging and diets remain poorly diversified, with as much as $80 \%$ of the dietary energy supply coming from rice alone [9].

Evaluation of energy productivity and efficiency of various field crops including wheat using various approaches are quite common in the literature $[10,11,12,13,14,15,16$, $17,18,19,20,21,22]$. However, a large number of these studies concentrated on evaluating energy productivity and energy ratio (which is also termed as energy use efficiency) by applying an accounting approach $[10,11,12,14,15,17,22]$. However, a limitation of the accounting approach is that it provides information on the observed use of inputs and outputs produced but cannot determine whether such outcome is technically efficient or not. In other words, this approach does not provide information on whether the farmers are using the 
minimum possible input levels to produce a given amount of output or producing a maximum possible level of output by using a given amount of inputs known as technically efficient production process.

Some of the recent studies have utilized a non-parametric programming approach, specifically Data Envelopment Analysis (DEA), to examine energy productivity and efficiency of crops $[16,21]$ which suffers from a disadvantage of attributing all errors and statistical noises to inefficiency and hence understates the level of true production performance of the individual producers. A few studies have also used parametric and/or econometric approach to examine energy productivity and efficiency of crops, but their procedures were largely confined to deterministic models which assume perfect technical efficiency in the production process $[18,19]$ which is not true as there is ample evidence of widespread inefficiency in the production process. Only recently, Rahman and Barmon [20] have used the stochastic input distance function model to estimate energy productivity and efficiency of 'gher' (prawn-rice-fish) farming system in Bangladesh that allows for inefficiency in the production process at the level of individual producers. Also Rahman and Rahman [13] applied stochastic production frontier model to estimate energy productivity and efficiency of maize cultivation in Bangladesh while accounting for the socio-economic and environmental factors affecting choice of the growing season (summer versus winter) as well as production performance of the farmers.

Wheat is a crop that is particularly sensitive to variations in the production environment as well as management practices. For example, a delay in sowing beyond the optimum period (i.e., Nov. 30 ${ }^{\text {th }}$ in Bangladesh) can result in a loss of yield @ 1.13\% per day [5]. But most of the studies in the literature examining energy productivity and efficiency in crop farming did not take into account any environmental constraints within which production occurs, thereby leading to biased results. This is because omission of the environmental constraints within which farmers operate result in omitted variable bias in the 
estimation procedure, thereby leading to biases in the parameter estimates of the production frontier, technical efficiency scores as well as the determinants of inefficiency $[23,24]$. The problem of such omission is even higher for wheat farming because of its high level of sensitivity to variations in the production environment as explained above.

Given this backdrop, we evaluate productivity and efficiency of energy use in wheat production, while accounting for the environmental constraints within which farmers operate. Specifically, we set out to measure: (a) energy productivity of wheat output while allowing for inefficiency at the level of individual farmers; (b) technical (energy) efficiency of wheat production; and (c) identify the socio-economic determinants of technical (energy) inefficiency. The specific contribution of this study to the existing energy literature is three fold: (a) first, we address these aforementioned objectives while explicitly accounting for the environmental constraints to affect productivity and provide a measure of their influence on the productivity level using a parametric approach (i.e., the stochastic production frontier approach) which in turn allows for inefficiency in the production process at the level of individual producers; (b) second, we demonstrate the magnitude of the bias in technical (energy) efficiency scores that results due to omission of the environmental constraints; and (c) third, the study also provides confirmation that wheat farming is highly efficient in energy use along with its financial merit or profitability [25]. This confirmation is important because not all crops that are deemed to be profitable are also efficient in terms of energy use. For example, Rahman and Barmon [20] noted that the prawn-fish enterprise of the gher farming system, which is the most financially rewarding enterprise, is actually highly inefficient in terms of energy use. The gher farming system as a whole passes the test of sustainability in terms of energy use because of the high level of energy ratio (or energy use efficiency) of the associated rice enterprise of the system. Therefore, it is important to judge the merit of a crop production system in terms of its energy use which serves as an indicator of its sustainability, particularly in an economy where energy deficiency is acute, such as Bangladesh. 


\section{Research Methods}

\subsection{The study area}

Although wheat is cultivated throughout Bangladesh, the production intensity differs substantially across regions. As such, we have constructed a wheat intensity index (WI) for each greater district ${ }^{1}$. The WI for the $j$ th district is given by:

$W I_{j}=\left(W A_{j} / G C A_{j}\right) * 100$,

where $W I$ is the index, $W A$ is the area cultivated with wheat and $G C A$ is the gross cropped area. The computed value of the index, which can also be regarded as the area share of wheat in GCA, is used to classify the regions into three levels of intensity: high intensity $(W I>8.0)$, medium intensity $(4.01<W I<8.0)$, and low intensity areas $(W I<4.0)$.

The selection of sampled farmers followed a multistage sampling procedure. First, two regions from the high intensity areas (Dinajpur and Rajshahi) and one region from the medium intensity area (Jamalpur) were purposively selected ${ }^{2}$. These three selected regions cover $37 \%$ of the total wheat area of Bangladesh for the year 2004 [6] and also represents three distinct agro-ecological zones (AEZ) of Bangladesh (i.e., AEZ-3, AEZ-11 and AEZ-9) ${ }^{3}$ (Table 1). Dinajpur is located in the north-west, Rajshahi in the mid-west and Jamalpur in the mid-north of Bangladesh. Second, one upazila (sub-district) from each district and one union from each upazila were randomly selected. Third, three mouzas (it is a measure of administrative jurisdiction corresponding to a specific land area which may contain more than one settlement/village) were selected at random to sample farm households. Also, a fourth

\footnotetext{
${ }^{1}$ This is because official data are available for 21 regions (former districts). Currently, there are 64 new districts in Bangladesh.

${ }^{2}$ We have excluded low intensity areas because we assumed that these regions have limited potential for wheat production. The low intensity areas are Kishoregonj, Mymensingh, Barisal, Patuakhali, Khulna, Noakhali, Sylhet, Chittagong, and Chittagong Hill tracts. Although rice is the principal crop in these districts, the first five districts are low lying areas prone to flooding and the latter three districts are hilly areas of the country.

${ }^{3}$ A total of 29 AEZs were identified in Bangladesh which cut across multiple regions.
} 
mouza was randomly selected to meet the required sample size due to insufficient households in one mouza. Fourth, representativeness of the selected sample is ensured by following a number of steps. This involved constructing a sampling frame of wheat farm holdings using record books at the union council office (lowest level of government administrative unit) and information provided by the village leaders as well as other key informants. The farms in the areas being studied were divided into three sizes by area [25]. Of the total of all farms in the areas being studied, 293 were selected for inclusion in the study. Pre-tested questionnaires were administered to collect the data in the first quarter of 2004 covering information for the wheat growing season of Nov-2003 to March-2004.

\section{[TABLE 1 ABOUT HERE]}

\subsection{Analytical framework}

As a first step, standard energy input output analysis $[10,11,12,15,17,22]$ is used to estimate some basic performance measures of the wheat farming system. These are defined as [22]:

Energy ratio $($ Energy use efficiency $)=$ Energy output $\left(\mathrm{MJ} \mathrm{ha}^{-1}\right) /$ Energy input $\left(\mathrm{MJ} \mathrm{ha}^{-1}\right)(1)$

Energy productivity $=$ Yield $\left(\mathrm{kg} \mathrm{ha}^{-1}\right) /$ Energy input $\left(\mathrm{MJ} \mathrm{ha}^{-1}\right)$

Specific energy $=$ Energy input $\left(\mathrm{MJ} \mathrm{ha}^{-1}\right) /$ Yield $\left(\mathrm{kg} \mathrm{ha}^{-1}\right)$

Net energy $=$ Energy output $\left(\mathrm{MJ} \mathrm{ha}^{-1}\right)-$ Energy Input $\left(\mathrm{MJ} \mathrm{ha}^{-1}\right)$

We applied standard energy coefficients from the existing published literature $[1,10$, $11,12,14,15,17,22]$ for conversion. Specifically, the production energy for power tiller and shallow tube wells (which are not available in the literature) were calculated as follows [12]:

$$
M_{p e}=\left(G M_{p}\right) /(T W)
$$

where $\mathrm{M}_{\mathrm{pe}}$ is the energy of the power tiller per unit area (MJ per ha); $\mathrm{G}$ is the mass of power tiller, $\mathrm{kg} ; \mathrm{M}_{\mathrm{p}}$ is the production energy of the power tiller, (MJ per $\mathrm{kg}$ ); $\mathrm{T}$ is the economic life, (hour); and $\mathrm{W}$ is the effective field capacity, (ha per hour).

The diesel energy requirement was determined on the basis of fuel consumption (litre 
per hour). The data were converted into energy units and expressed in MJ per ha. Fuel consumption was computed as [12]

$$
F C=P_{m} \cdot R \cdot S F C
$$

where FC is the fuel consumption, (litre per hour); $\mathrm{P}_{\mathrm{m}}$ is the machine power, $\mathrm{kW}$; $\mathrm{R}$ is the loading ratio, decimal; and SFC is the specific fuel consumption ( 0.25 litre $\mathrm{kW}$ per hour).

Table 2 presents the energy coefficients used in this study including literature sources.

\section{[TABLE 2 ABOUT HERE]}

\subsubsection{The econometric approach: Stochastic production frontier}

We have applied an extended stochastic production frontier model which includes environmental factors as additional regressors following Sherlund et al [23] and Rahman and Hasan [24] for the reasons explained earlier. The model for the $i$ th farmer is written as [23]:

$$
Q_{i}=f\left(X_{i}, E_{i}\right)-u_{i}+v_{i}
$$

where $Q_{i}$ is the energy output, $X_{i}$ is the vector of physical energy inputs, $E_{i}$ is the vector of relevant environmental variables affecting production, $v_{i}$ is assumed to be $I I D N\left(0, \sigma^{2}\right)$ double sided random error, independent of the $u_{i}$; and the $u_{i}$ is a non-negative random variable $\left(u_{i} \geq 0\right)$, representing production inefficiency which is assumed to be $I D$ as truncation at zero of the normal distribution with mean $-Z_{i} \cdot \delta$, and variance $\sigma_{u}^{2}\left(\mid N\left(-Z_{i} \delta, \sigma_{u}^{2} \mid\right)\right.$, where $Z_{i}$ are the correlates of inefficiencies on farm $i$.

We have applied the single stage approach to identify the predictors of technical (energy) efficiency, wherein the technical inefficiency parameter is related to a vector of farmlevel socio-economic characteristics subject to statistical error, as follows [26]:

$u_{i}=Z_{i} \delta+\zeta_{i} \geq 0$

where, $Z_{i}$ s are the variables representing socio-economic characteristics of the farmers and the error $\zeta_{i}$ is distributed as $\zeta_{i} \sim N\left(0, \sigma_{\zeta}^{2}\right)$. Since $u_{i} \geq 0, \zeta_{i} \geq-Z_{i} \delta$, and the distribution of $\zeta_{i}$ is truncated from below at the variable truncation point, $-Z_{i} \delta$.

The production efficiency of farm $i$ is defined as [26]: 
$E F F_{i}=E\left[\exp \left(-u_{i}\right) \mid \xi_{i}\right]=E\left[\exp \left(-\delta_{0}-\sum Z_{i} \delta \mid \xi_{i}\right)\right.$

where $E$ is the expectation operator. This is achieved by obtaining the expressions for the conditional expectation $u_{i}$ upon the observed value of $\xi_{i}$, where $\xi_{i}=v_{i}-u_{i}$. We apply the Maximum Likelihood Estimation (MLE) procedure for estimation of the unknown parameters. The likelihood function is expressed in term of the variance parameters, $\sigma^{2}=\sigma_{v}{ }^{2}$ $+\sigma_{u}^{2}$ and $\gamma=\left(\sigma_{u}^{2} / \sigma^{2}\right)[26]$.

\subsubsection{The empirical model}

The empirical model is specified with a flexible and extended Translog stochastic production frontier function allowing for all possible interaction amongst physical energy inputs and environmental constraints. However, in order to preserve the degrees of freedom, we did not allow interaction between physical energy inputs and environmental constraint variables. The model is written as [24]:

$$
\begin{aligned}
\ln Q_{i}= & \alpha_{0}+\sum_{j=1}^{7} \alpha_{j} \ln X_{i j}+\sum_{j=1}^{7} \sum_{k=1}^{7} \beta_{j k}\left(\ln X_{i j} \ln X_{i k}\right)+\sum_{l=1}^{3} \varphi_{l} \ln E_{i l}+\sum_{l=1}^{3} \sum_{m=1}^{3} \phi_{l m}\left(\ln E_{i l} \ln E_{i m}\right) \\
& +\sum_{t=1}^{2} \tau_{t} D_{i t}+v_{i}-u_{i}
\end{aligned}
$$

and

$u_{i}=\delta_{0}+\sum_{d=1}^{13} \delta_{d} Z_{i d}+\zeta_{i}$

where $Q_{i}$ is the energy output of wheat (including energy equivalent of straw output); $X_{i j}$ is $j$ th energy input for the $i$ th farmer; $E_{i l}$ are the environmental constraints, $D_{i t}$ are the dummy variables representing two regions (Rajshahi and Jamalpur); $v_{i}$ is the two sided random error, $u_{i}$ is the one sided half-normal error, In natural logarithm, $Z_{i d}$ variables representing farm level socio-economic characteristics to explain inefficiency, $\zeta_{i}$ is the truncated random variable; $\alpha_{0}, \alpha_{j}, \beta_{j}, \tau_{m}, \delta_{0}, \varphi_{k}$ and $\delta_{d}$ are parameters which must be estimated.

A total of seven physical production inputs $(X)$ and three environmental constraint variables $(E)$ were used in the production function, and 13 variables representing socio- 
economic characteristics of the farmers $(Z)$ were included in the inefficiency effects model as predictors of technical inefficiency.

Inclusion of the seven physical production input represents a complete range of inputs used in the production of wheat, and therefore, unlikely to render any omitted variable bias in the modelling process. Also inclusion of the variables representing farmers' socio-economic circumstances as predictors of inefficiency is largely based on the existing literature as well as expert opinion from the Wheat Research Centre of the Bangladesh Agricultural Research Institute (BARI).

Construction of the various indices followed a simple procedure to convert the measures into ascending values of integer numbers starting from a value of 1 . For example, the composite index of 'other environmental constraint' variable is constructed as follows. Farmers were asked to provide their own estimates of the percentage of crop yield lost due to individual effects of (a) insect and pest attacks, (b) weed infestation, (c) weather variations such as drought or storm, (d) delay in sowing, and (e) poor soil fertility. These percentages of crop yield loss were first aggregated and then indexed into integers as explained in Table 3. The definitions and measures of all the variables used in the analysis are presented in Table 3.

\section{[TABLE 3 ABOUT HERE]}

\section{Results}

\subsection{Energy inputs and outputs in wheat farming}

First part of the Table 3 presents energy use levels of wheat farming. We see that the dominant energy using input is inorganic fertilizers accounting for $43.6 \%$ of total input use, as expected. The figure is closely comparable to fertilizer use in wheat at $45.4 \%$ [17], potato at $46 \%$ [8], rice at 36\% [15] and corn at 33\% [16]. However, Bangladeshi farmers also use organic fertilizers (i.e., compost of cow dung) up to $8.6 \%$ of total input energy use which is not commonly reported in the literature. For example, Mani et al. [17] reported use of organic manure for maize at $20 \%$ of total energy input in India but none for wheat. Overall, the 
energy output produced from wheat production is substantially higher than the energy consumed as inputs, which is encouraging.

The results presented in Table 4 clearly establish that wheat farming passes the test of sustainability when evaluated in terms of energy use. The net energy balance is estimated about 20,596 MJ per ha and the energy ratio (or energy use efficiency) is estimated about 2.34, implying that wheat farming in Bangladesh is quite energy efficient. However, this figure is quite low when compared with energy balance of wheat at 46,195 MJ per ha in India [17].

\section{[TABLE 4 ABOUT HERE]}

\subsection{Energy productivity of wheat farming}

Results of the joint estimation of the stochastic production frontier and inefficiency effects models (Eqs. 10 and 11) using MLE procedure is reported in Table 6. The truncated normal model thus specified achieved convergence after 59 iterations. The convergence criteria or the tolerance limit for the parameters and slope gradients were set at $10^{-4}$. A number of hypothesis tests were also conducted to: (a) determine model choice, (b) justify inclusion of the environmental factors, (c) detect presence of inefficiency in the model, and (d) identify the predictors of inefficiency (see Table 5). Choice of the functional form involves testing suitability of the Cobb-Douglas vs Translog functions. This was done by testing whether all second order coefficients are jointly zero $\left(H_{0}: \beta_{11}=\beta_{12}=\ldots .=\beta_{67}=\varphi_{11}=\varphi_{12}=\ldots .=\varphi_{23}=\right.$ $0)$. The null-hypothesis was strongly rejected at the $1 \%$ level of significance $(p<0.01)$. The implication is that there are non-linearities in the production function and, hence, the Translog model is a better specification of the true production structure. Next, we test whether 'the environmental variables included are jointly zero' $\left(H_{0}: \varphi_{1}=\varphi_{2}=\ldots .=\varphi_{23}=0\right)$. The null-hypothesis was again strongly rejected at the $1 \%$ level of significance $(\mathrm{p}<0.01)$, thereby, indicating that the environmental factors significantly affect wheat (energy) productivity as emphasized earlier. The test of $\gamma$ is also strongly rejected suggesting presence 
of technical inefficiency, thereby justifying use of the stochastic production frontier approach for our analysis (see Table 6).

Four of the seven inputs significantly influence wheat (energy) productivity. The input variables were mean corrected prior to estimation $\left(X_{i j}-\bar{X}_{j}\right)$. Therefore, the coefficients on the first order terms of these variables represent elasticities. However, for ease of exposition we presented these production elasticities in Table 7. Energy from machinery (mechanical power and irrigation) has the highest elasticity followed by energy from inorganic fertilizers which perhaps explain rapid rise in the use of commercial energy in Bangladesh agriculture. The elasticity value shows that a $1 \%$ increase in irrigation will increase wheat (energy) output by $0.12 \%$ followed by fertilizers at $0.11 \%$. Also, the use of organic fertilizer significantly influences wheat productivity, although the coefficient is small.

\section{[TABLES 5, 6 and 7 ABOUT HERE]}

Turning to the influence of the variables representing environmental constraints on wheat production, we see that planting in unsuitable lands and the index of 'environmental constraints' (which is made up of planting delay, weed and pest attack, bad weather and planting in infertile soils) significantly reduces wheat (energy) productivity. The effect of planting in unsuitable lands is particularly high with an elasticity value of -0.11 . The implication is that a $1 \%$ increase in the index of land unsuitability will reduce wheat (energy) productivity by $0.11 \%$. Similarly, a $1 \%$ increase in the composite index of 'environmental constraint' will reduce wheat (energy) productivity by $0.04 \%$. Therefore, the combined effect of a $1 \%$ increase in the indices of environmental constraints on energy productivity of wheat is $-0.15 \%$. These variables are often ignored in most of the studies with few exceptions $[13$, $23,24]$, which should not be the case as they exert considerable influence on productivity of crops. Since we have included environmental constraints in the model, the effects of the key physical energy inputs on wheat (energy) productivity are relatively more accurate. Both 
Sherlund et al. [23] and Rahman and Hasan [24] reported rise in output and fall in inputs of labour and/or fertilizers after accounting for environmental factors.

\subsection{Technical (energy) efficiency of wheat farmers}

The average technical (energy) efficiency score of wheat production is $88 \%$. The implication is that wheat (energy) output can be increased by up to $12 \%$ by eliminating technical inefficiency (see Table 8 and Figure 1). The minimum score is $60 \%$ and the maximum is $100 \%$. Accounting for the environmental constraints significantly improves technical energy efficiency by 3 percentage points $(p<0.01)$, thereby validating our claim that inefficiency is overstated when environmental factors are omitted from the analysis ${ }^{4}$ (see Table 8). Our estimate of technical energy efficiency is closely comparable for rice at 0.90 in Iran [21], 0.92 for rice in India [14], and 0.85 for soybean in Iran [20].

\section{[TABLE 8 and FIGURE 1 ABOUT HERE]}

\subsection{Determinants of technical (energy) efficiency}

A host of socio-economic factors, particularly management practices of wheat farming, significantly affect technical (energy) efficiency. The null hypotheses that the 'socioeconomic factors are jointly zero' $\left(H_{0}: \delta_{1}=\delta_{2}=\ldots . .=\delta_{13}=0\right)$ is strongly rejected (see Table 5), implying that technical (energy) efficiency in wheat farming is highly sensitive to management practices, as expected. For example, a delay in sowing and application of the first dose of fertilizers significantly decrease (energy) efficiency. Also, use of mechanical power reduces efficiency which is puzzling. One reason may be that Bangladesh has resorted to the use of power tiller only recently due to severe shortage of bullock power in various parts of the country. Therefore, farmers are not well equipped with the new technology and perhaps overuse it. However, farmers' education, sources of agricultural information and training in wheat production significantly increase technical (energy) efficiency. Although the

\footnotetext{
${ }^{4}$ We did not report details of the parameter estimates of the model without environmental constraints variables in order to save space.
} 
role of education on improving technical efficiency of farming is mixed in Bangladesh, Asadullah and Rahman [27] using a large set of data concluded that education has a significant influence on improving technical efficiency in Bangladeshi rice farming which is also found in our results. Also, it is encouraging to note that diverse sources of information and skills improvement through training have a positive influence on technical energy efficiency.

\section{Conclusions}

The principal aim of this study was to examine whether wheat farming in Bangladesh, that have been growing remarkably over the past four decades, is productive and efficient in terms of energy use. We find that the system is highly energy efficient. The net energy balance of wheat farming is estimated about 20,596 MJ per ha and energy ratio is estimated about 2.34.

Farmers work within the limitation posed by the production environment which are important but are generally ignored in the efficiency literature, thereby, leading to biased estimates of the production coefficients, efficiency scores and predictors of inefficiency. We have clearly demonstrated that the environmental factors significantly influence productivity as well as technical (energy) efficiency of wheat production in Bangladesh. Planting in unsuitable lands, and a combination of infertile soils, weed attack, weather variation and a delay in sowing significantly reduce wheat energy output.

Technical (energy) efficiency of wheat production in Bangladesh is estimated at $88 \%$, implying that wheat (energy) output can be increased by $12 \%$ through reallocation of resources alone. The farmers at the lower end of the efficiency score distribution could improve their wheat (energy) output even further by optimizing their resource use pattern as done by their best performing peers (i.e., those who are producing at the efficiency level of 100\%). Farmers' education, access to agricultural information and training significantly improves technical efficiency, whereas events such as a delay in sowing and fertilization significantly reduce it. 
A number of policy implications can be drawn from this study. First, land suitability is a major constraint which needs to be addressed effectively. One way is to improve soil quality by encouraging both soil conservation measures as well as crop rotations (e.g., planting legumes, i.e., pulses and oilseeds, which improve soil quality). 'No till' farming can also be adopted which improves wheat yield, improves soil and reduces commercial energy (e.g., diesel fuel) requirements [14, 29]. Alternatively, research effort should focus on developing varieties that are suitable for marginal areas so that the farmers who are compelled to plant their crops in unsuitable lands can also benefit from these new varieties. Second, develop wheat varieties that are resistant to adverse environmental factors (e.g., weed and weather resistant). The Wheat Research Centre of Bangladesh has already developed some varieties that are weed resistant, but these should be effectively disseminated at the farm level. In our study, $94 \%$ of the total sampled farmers used only one variety called 'Kanchan' that was released in 1983, which reflects weak level of dissemination of research innovations at the farm level. Third, improve management practices (e.g., sowing and fertilizing on time) which can be achieved through investments in extension services, training programs and information dissemination mechanisms. Fourthly, investing in farmers' education seems crucial.

Achievement of these policies is challenging for Bangladesh. Nevertheless, an increase in wheat production is a desirable goal to combat food insecurity as we have proved that the system is highly sustainable over the long run when evaluated in terms of energy use. 


\section{References}

[1] Ozkan B, Ceylan RF, Kizilay H. Energy inputs and crop yield relationships in greenhouse winter crop tomato production. Renewable Energy, 2011, 36: 3217-3221.

[2] Bain SK. Indicators of energy use and efficiency in Bangladesh. Paper presented at the Bangladesh Economic Association Conference (BEA-2007), Dhaka, Bangladesh. http://bdeconassoc.org/userfiles/pdf/39\%20Energy\%20------\%20Perspectives \%20Paper_Subrata\%20K\%20B.pdf (accessed on 24/12/2011).

[3] Khosruzzaman S, Asgar M, Rehman KMR, Akbar S. Energy intensity and productivity in relation to agriculture: Bangladesh perspective. Journal of Bangladesh Academy of Sciences, 2010, 34: 59-70.

[4] Hanson H, Borlaug NE, Anderson RG. Wheat in the third world. Westview press, Boulder, Colorado, USA. 1982. pp 174.

[5] Rahman S, Hasan MK. Wheat in Bangladesh: Yield growth, production performance and determinants. Environmental Research Journal, 2011, 5: 1-21.

[6] BBS. Statistical Yearbook of Bangladesh, 2009. Bangladesh Bureau of Statistics, Dhaka, Bangladesh. 2010.

[7] Morris M, Chowdhury N, Meisner C. Economics of wheat production in Bangladesh. Food Policy, 1996, 21: 541-560.

[8] Pimentel D, Houser J, Preiss E, White O, Fang H, Mesnick L, Barsky T, Tariche S, Schreck J, Alpert S. Water Resources: Agriculture, the Environment, and Society, BioScience, 1997, 47: 97-106.

[9] FPMU. National Food Policy Plan of Action (2008-2015). Food Planning and Monitoring Unit, Ministry of Food and Disaster Management, Dhaka, Bangladesh. 2008. Available @ NationalFoodPolicyPlanofActionFINAL.pdf 
[10] Ghorbani R, Mondani F, Amirmoradi S, Feizi H, Khorramdel S, Teimouri M, Sanjani S, Anvarkhah S, Aghel H. A case study of energy use and economical analysis of irrigated and dryland wheat production systems. Applied Energy, 2011. 88: 283-288.

[11] Mohammadi A, Tabatabaeefar A, Shahin S, Rafiee S, Keyhani A. Energy use and economical analysis of potato production in Iran a case study: Ardabil province. Energy Conversion and Management, 2008, 49: 3566-3570.

[12] Canakci M, Topakci M, Akinci I, Ozmerzi A. Energy use pattern of some field crops and vegetable production: Case study for Antalya Region, Turkey. Energy Conversion and Management, 2005, 46: 655-666.

[13] Rahman S, Rahman MS. Energy productivity and efficiency of maize accounting for the choice of growing season and environmental factors: an empirical analysis from Bangladesh. Energy, 2013, 49: 329-336.

[14] Tabatabaeefar A, Emamzadeh H, Varnamkhasti MG, Rahimizadeh R, Karimi M. Comparison of energy of tillage systems in wheat production. Energy. 2009. 34:4145.

[15] Pishgar-Komleh SH, Sefeedpari, P, Rafiee S. Energy and economic analysis of rice production under different farm levels in Guilan province of Iran. Energy, 2011, 36: $5824-5831$.

[16] Banaeian N, Zangeneh M. Study on energy efficiency in corn production of Iran. Energy, 2011, 36: 5394-5402.

[17] Mani I, Kumar P, Panwar JS, Kant K. Variation in energy consumption in production of wheat-maize with varying altitudes in hilly regions of Himachal Pradesh, India. Energy 2007, 32: 2336-2339.

[18] Singh S, Singh S, Mittal JP, Pannu CJS. Frontier energy use for the cultivation of wheat crop in Punjab. Energy Conversion and Management, 1998, 39: 485-491. 
[19] Hamedani SR, Shabani Z, Rafiee S. Energy inputs and crop yield relationship in potato production in Hamadan province of Iran. Energy, 2011, 36: 2367-2371.

[20] Rahman S, Barmon, BK. Energy productivity and efficiency of the 'gher' (prawn-fishrice) farming system in Bangladesh. Energy, 2012, 43: 293-300.

[21] Nassiri SM, Singh S. Study on energy use efficiency for paddy crop using data envelopment analysis (DEA) technique. Applied Energy, 2009, 86: 1320-1325.

[22] Unakitan G, Hurma H, Yilmaz, F. An analysis of energy use efficiency of canola production in Turkey. Energy, 2010, 35: 3623-3627.

[23] Sherlund SM, Barrett CB, Adesina AA. Smallholder technical efficiency controlling for environmental production conditions. Journal of Development Economics, 2002, 69: $85-101$.

[24] Rahman S, Hasan MK. Impact of environmental production conditions on productivity and efficiency: the case of wheat producers in Bangladesh. Journal of Environmental Management. 2008, 88: 1495-1504.

[25] Rahman S, Hasan MK. Wheat in Bangladesh: Profitability, production practices and environmental and managerial factors affecting yield. In Almeida, M.T. (ed) Wheat: Genetics, crops and food production. Nova Science Publishers, Inc., New York, USA. 2011. p.315-331...

[26] Battese GE, Coelli TJ. A model for technical inefficiency effects in a stochastic frontier production function for panel data, Empirical Economics, 1995, 20: 325-332.

[27] Asadullah MN, Rahman S. Farm productivity and efficiency in rural Bangladesh: the role of education revisited. Applied Economics, 2009, 41: 17-33.

[28] Iqbal T. Energy input and output for production of Boro rice in Bangladesh. EJEAFChe (Electronic Journal of Environmental, Agricultural and Food Chemistry). 2008, 7: $2717-2722$. 
[29] Jin H, Hongwen L, Rasaily RG, Qingjie W, Guohua C, Yanbo S, Xiaodong Q, Lijin 1. Soil properties and crop yields after 11 years of no tillage farming in wheat-maize cropping system in North China Plain. Soil \& Tillage Research. 2011, 113: 48-54. 


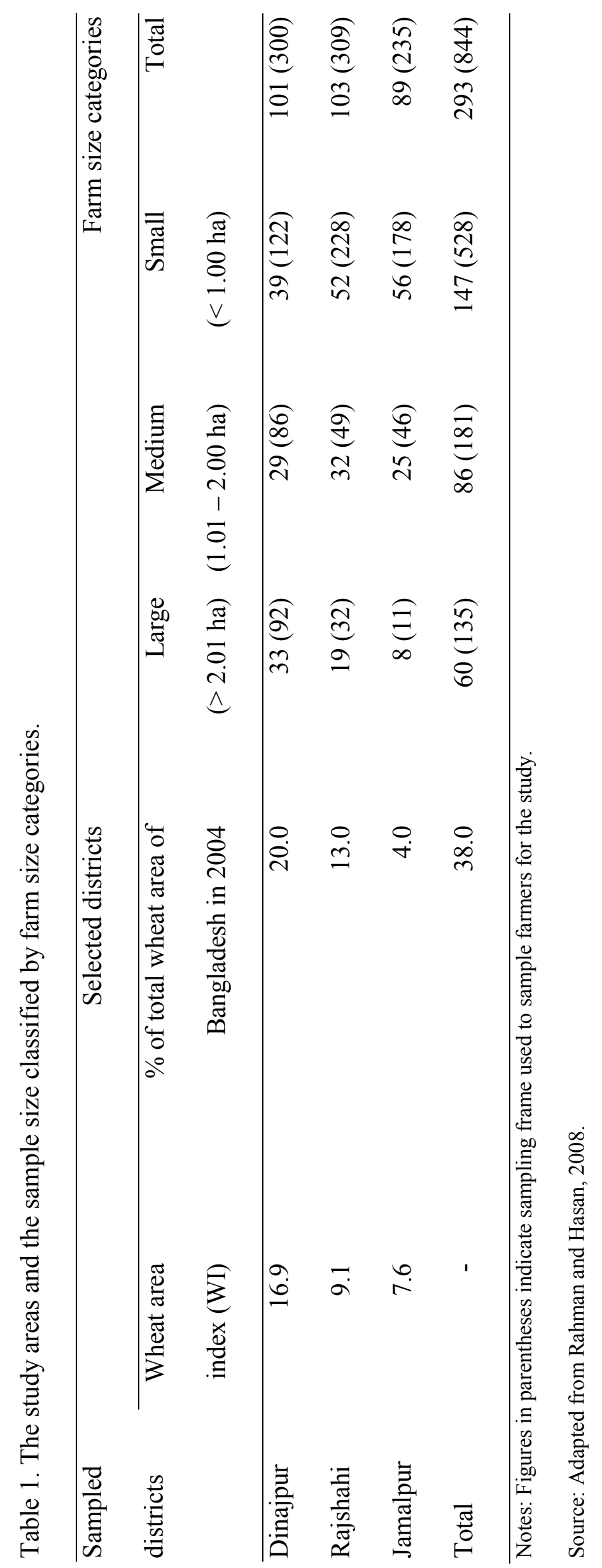


Table 2. Energy coefficients used for wheat cultivation

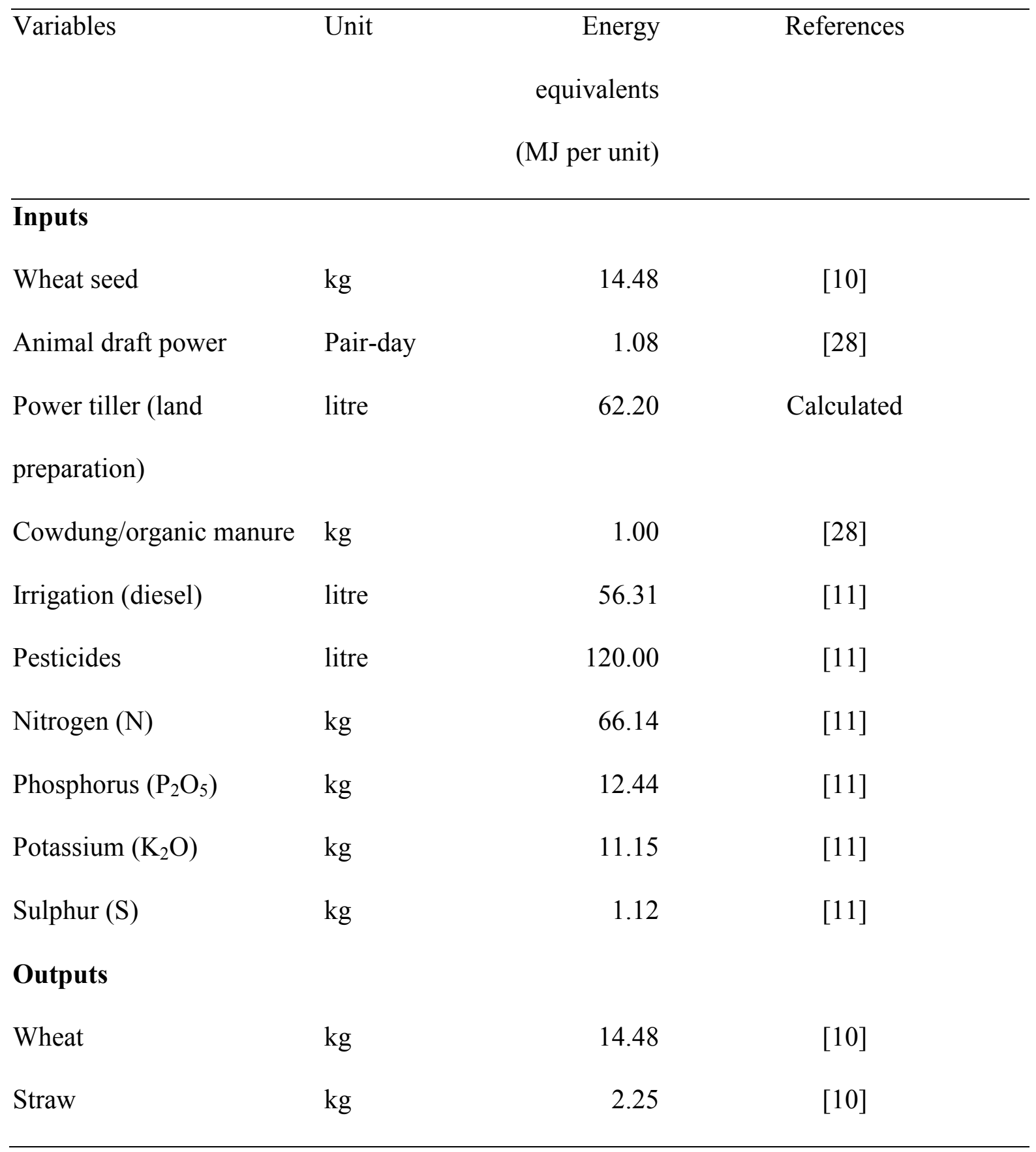




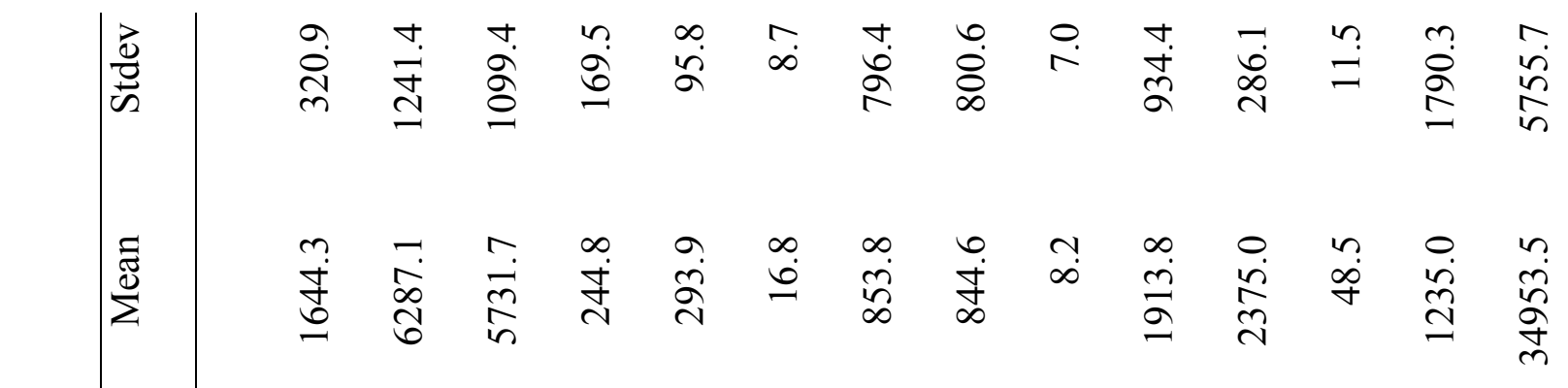

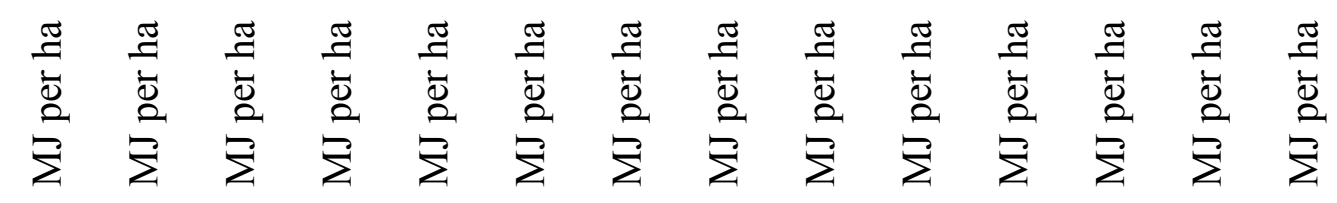

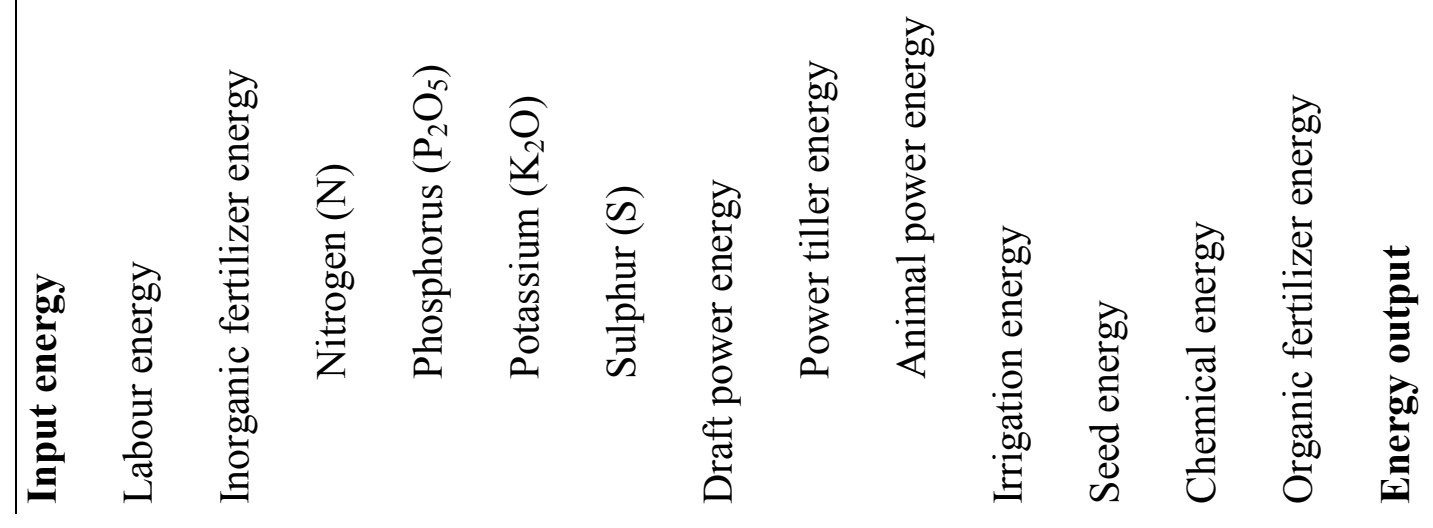




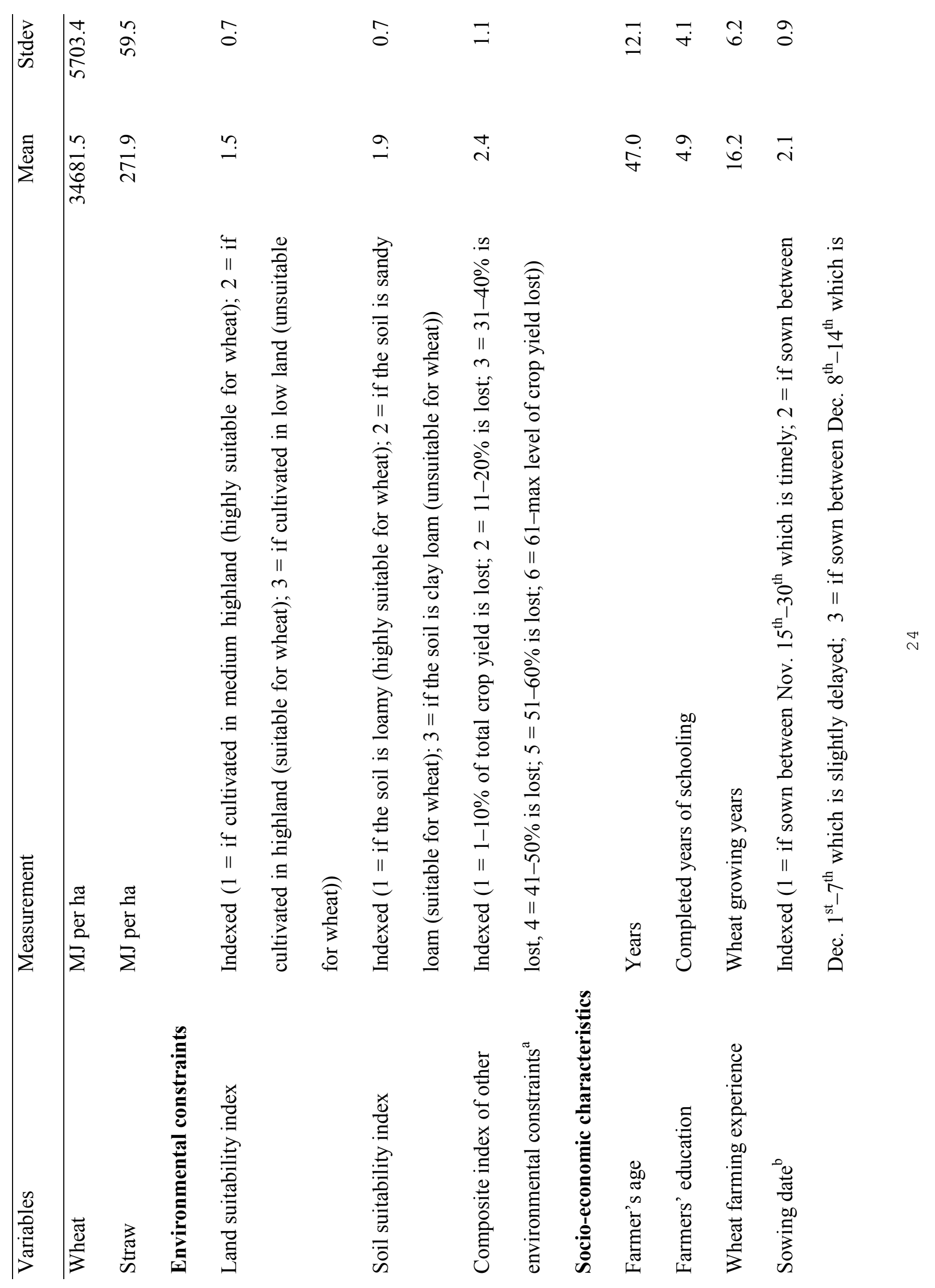




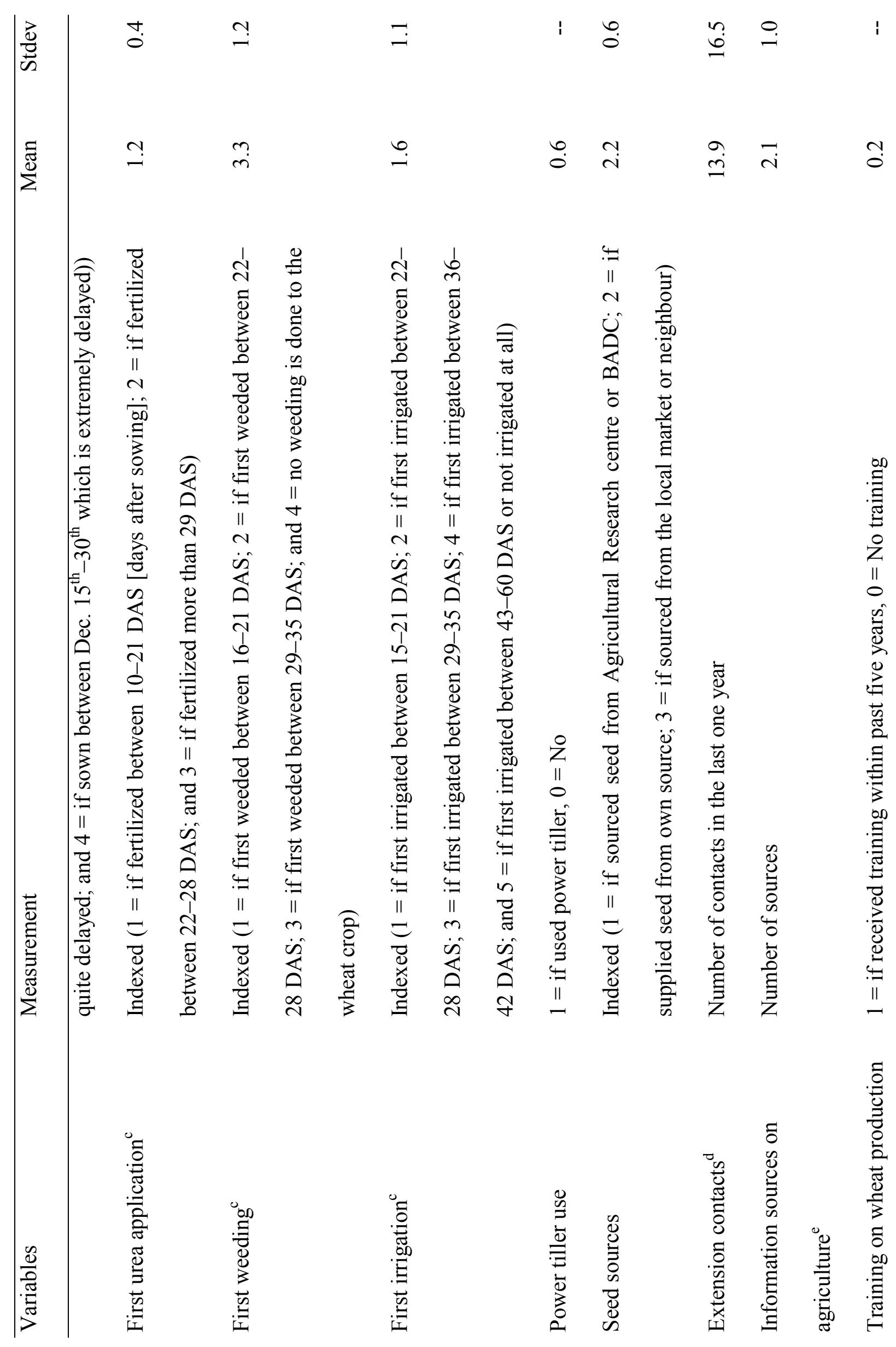




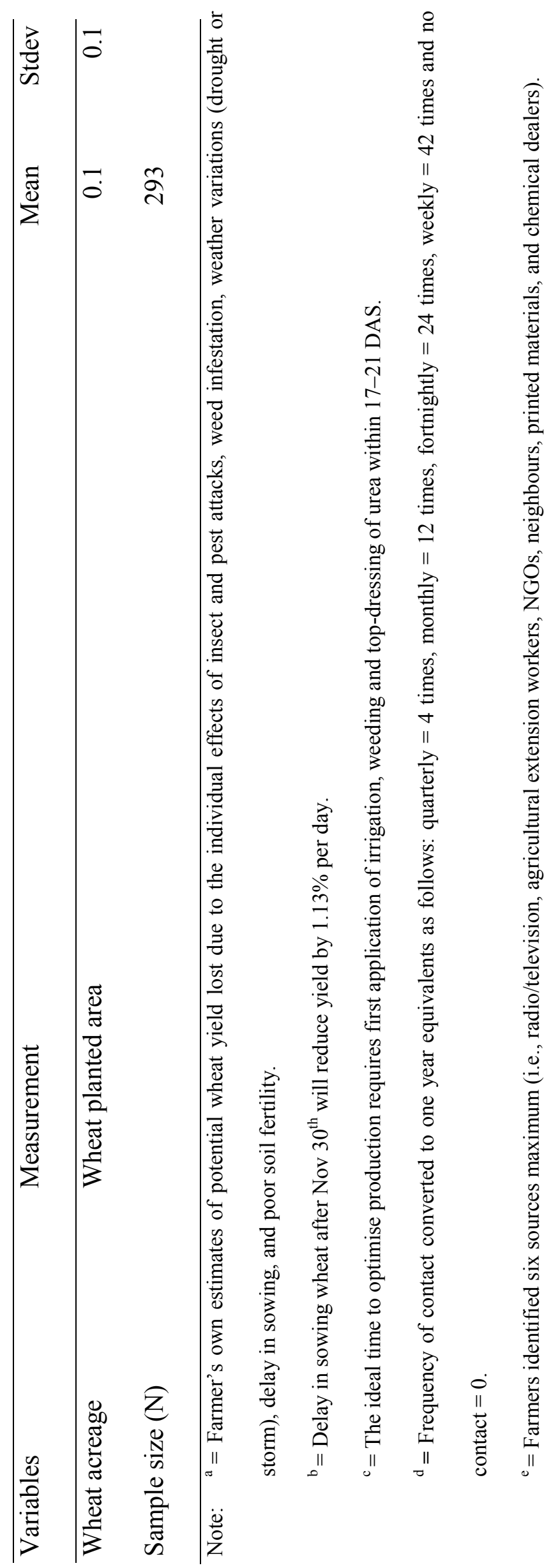


Table 4. Energy accounts in wheat cultivation

\begin{tabular}{lcr}
\hline Measurements & Unit & Mean \\
\hline Energy input & MJ per ha & 14357.6 \\
Energy output & MJ per ha & 34953.5 \\
Wheat yield & kg per ha & 2395.1 \\
Specific energy & MJ per kg & 6.0 \\
Energy ratio (Energy use efficiency) & - & 2.3 \\
Energy productivity & kg per MJ & 0.2 \\
Net energy & MJ per ha & 20595.9
\end{tabular}


Table 5. Hypothesis tests

$$
\chi^{2}(\mathrm{v}, 0.95) \text { Ratio statistic }
$$

Selection of the functional form

$\left(H_{0}: \beta_{11}=\beta_{12}=\ldots .=\beta_{67}=\varphi_{11}=\varphi_{12}\right.$

$\left.=\ldots .=\varphi_{23}=0\right)$

No effect of environmental constraints

$\left(H_{0}: \varphi_{1}=\varphi_{2}=\ldots .=\varphi_{23}=0\right)$

Presence of inefficiency in the model

Reject $H_{0}$

$\left(H_{0}: \gamma=0\right)$

No effect of socio-economic

$22.36 \quad 142.55^{* * *}$

Reject $H_{0}$

$41.34 \quad 1350.16^{* * *} \quad$ Reject $H_{0}$

$14.07 \quad 630.29 * * * \quad$ Reject $H_{0}$

acteristies on inefficiency

$\left(H_{0}: \delta_{1}=\delta_{2}=\ldots .=\delta_{13}=0\right)$

Note: $\quad * * *$ significant at $1 \%$ level $(\mathrm{p}<0.01)$ 
Table 6. Maximum likelihood estimates of the stochastic production frontier for wheat

Variables $\quad$ Parameters Coefficients t-ratios

\section{Energy productivity function}

Intercept

$\alpha_{0} \quad 10.5571^{* * *}$

30.12

ln Labour energy

$\alpha_{1} \quad 0.0380$

In Inorganic fertilizer energy

$\alpha_{2} \quad 0.1051^{* * *}$

4.14

ln Mechanical energy

$\alpha_{3} \quad 0.0200^{* * *}$

ln Irrigation energy

$\alpha_{4} \quad 0.1242^{* * *}$

10.70

$\ln$ Seed energy

$\alpha_{5} \quad 0.0308$

0.74

ln Chemical energy

$\alpha_{6} \quad-0.0372$

$-1.46$

ln Organic fertilizer energy

$\alpha_{7} \quad 0.0046^{* * *}$

$0.5 \times(\ln \text { Labour })^{2}$

$\beta_{11}$

0.1427

0.49

$0.5 \times(\ln \text { Inorganic fertilizers })^{2}$

$\beta_{22}$

$-0.6427 * * *$

$0.5 \times{\text { (ln Mechanical power })^{2}}^{2}$

$\beta_{33} \quad-0.0089$

$0.5 \times(\ln \text { Irrigation })^{2}$

$\beta_{44} \quad-0.7156^{* *}$

$0.5 \times(\ln \text { Seed })^{2}$

$\beta_{55} \quad 0.0154 * * *$

$0.5 \times(\ln \text { Chemicals })^{2}$

$\beta_{66} \quad 0.0143$

$0.5 \times(\ln \text { Organic fertilizers })^{2}$

$\beta_{77}-0.0042 * * *$

$\ln$ Labour $x \ln$ Inorganic fertilizers

$\beta_{12} \quad-0.2373$

ln Labour x ln Mechanical power

$\beta_{13} \quad-0.0057$

$\ln$ Labour x $\ln$ Irrigation

$\beta_{14} \quad-0.3476^{*}$

$-1.65$

$\ln$ Labour x $\ln$ Seed

$\beta_{15} \quad 0.0277$

0.72

ln Labour x ln Chemicals

$\beta_{16} \quad 0.0211$

ln Labour x $\ln$ Organic fertilizers

$\beta_{17}-0.0123^{*}$ 
ln Inorganic fertilizer $x \ln$ Mechanical power

$\begin{array}{lll}\beta_{23} & -0.0562^{* * *} & -2.78 \\ \beta_{24} & -0.1195 & -0.65 \\ \beta_{25} & 0.0459^{*} & 1.78 \\ \beta_{26} & 0.0220 & 1.06 \\ \beta_{27} & -0.0287^{* * *} & -4.69 \\ \beta_{34} & -0.0279 & -1.18 \\ \beta_{35} & 0.0066^{*} & 1.71 \\ \beta_{36} & 0.0037 & 0.60 \\ \beta_{37} & -0.0003 & -0.41 \\ \beta_{45} & 0.0126 & 0.41\end{array}$

ln Irrigation $x \ln$ Seed

$\beta_{46} \quad-0.0192$

ln Irrigation $\mathrm{x} \ln$ Chemicals

$\beta_{46} \quad-0.0192$

$\ln$ Irrigation $\mathrm{x} \ln$ Organic fertilizers

$\beta_{47} \quad-0.0391 * * *$

$\ln$ Seed $x \ln$ Chemicals

$\beta_{56} \quad 0.0076$

$\ln$ Seed x ln Organic fertilizers

$\beta_{57} \quad 0.0034^{* *}$

$-0.12$

ln Chemicals x ln Organic fertilizers

$\beta_{67} \quad-0.0001$

\section{Environmental constraints}

ln Land suitability

$\varphi_{1} \quad-0.1081 * * *$

$\ln$ Soil suitability

$$
\varphi_{2} \quad-0.0034
$$

In Environmental Constraints

$\varphi_{3} \quad-0.0405^{* * *}$

$0.5 \times(\ln \text { Land suitability })^{2}$

$\varphi_{11} \quad 0.2267 * * *$

$0.5 \times(\ln \text { Soil suitability })^{2}$

$\varphi_{22} \quad 0.0375$

$0.5 \times$ (ln Environmental constraints) ${ }^{2}$

$\varphi_{33}-0.1013 * * *$

$\ln$ Land suitability x $\ln$ Soil suitability

$\varphi_{12} \quad-0.0509^{*}$

ln Land suitability x ln Environmental constraints

$\varphi_{13} \quad 0.0329$ 
Variables

Parameters Coefficients

t-ratios

ln Soil suitability x ln Environmental constraints

Rajshahi region

Jamalpur region

Model diagnostics

$\sigma^{2}=\sigma_{u}^{2}+\sigma_{v}^{2}$

$\gamma=\sigma_{\mathrm{u}}^{2} /\left(\sigma_{\mathrm{u}}^{2}+\sigma_{\mathrm{v}}^{2}\right)$

Log likelihood

Wald $\chi^{2}$ (46 d.f.)

\section{Inefficiency determinant function}

Intercept

Farmer's age

Farmers' education

Wheat farming experience

Sowing date

First urea application

First weeding

First irrigation

Power tiller use

Seed sources

Extension contacts

Information sources on agriculture

Training on wheat production

Wheat acreage $\sigma^{2} \quad 0.0054^{* * *}$

$\gamma \quad 0.99 * * *$

439.72

$\varphi_{23} \quad 0.0032$

$\begin{array}{ll}\tau_{1} & 0.0114\end{array}$

0.45

$\tau_{2} \quad 0.0464 * * *$

5.83

$4120.00 * * *$

$\begin{array}{lll}\delta_{0} & -0.0565 & -1.24\end{array}$

$\begin{array}{lll}\delta_{1} & 0.0001 & 0.22\end{array}$

$\begin{array}{lll}\delta_{2} & -0.0049^{* * *} & -3.36\end{array}$

$\delta_{3} \quad-0.0001$

$-0.10$

$\delta_{4} \quad 0.0602 * * *$

8.51

$\delta_{5} \quad 0.0404 * * *$

2.64

$\delta_{6} \quad-0.0054$

$-0.65$

$\delta_{7} \quad-0.0050$

$-0.92$

$\delta_{8} \quad 0.1440 * * *$

6.79

$\delta_{9} \quad-0.0001$

$-0.01$

$\delta_{10} \quad 0.0000$

$-0.09$

$\begin{array}{lll}\delta_{11} & -0.0153^{* *} & -2.06\end{array}$

$\delta_{12} \quad-0.0325^{*}$

$-1.77$

$\delta_{13} \quad-0.0998$

$-0.95$ 
Note: $\quad * * *$ significant at $1 \%$ level $(\mathrm{p}<0.01)$;

** significant at $5 \%$ level $(\mathrm{p}<0.05)$;

* significant at $10 \%$ level $(\mathrm{p}<0.10)$ 
Table 7. Energy output elasticities

\begin{tabular}{llr}
\hline Variables & Coefficients & t-ratios
\end{tabular}

\section{Energy inputs}

Labour energy

0.0380

1.36

Inorganic fertilizer energy

$0.1051 * * *$

4.14

Mechanical energy

$0.0200 * * *$

3.26

Irrigation energy

$0.1242 * * *$

10.07

Seed energy

0.0308

0.74

Chemical energy

$-0.0372$

$-1.46$

Organic fertilizer energy

$0.0046 * * *$

3.17

\section{Environmental constraints}

Land suitability

$-0.1081 * * *$

Soil suitability

$-0.0034$

$-0.31$

Other environmental constraints

$-0.0405 * * *$

$-5.31$

Note: $\quad * * *$ significant at $1 \%$ level $(\mathrm{p}<0.01)$ 
Table 8. Technical (energy) efficiency scores

Items $\quad$ Model without accounting for Model with accounting for the the environmental constraints environmental constraints

\section{Energy efficiency distribution}

upto $70 \%$

$71-80 \%$

17.70

14.00

$81-90 \%$

42.00

42.00

$91 \%$ and above

34.50

42.30

\section{Energy efficiency statistics}

Mean value

0.85

0.88

Standard deviation

0.07

0.08

Minimum

0.56

0.60

Maximum

0.99

Mean difference (With vs

without environmental variables)

t-test for mean difference 


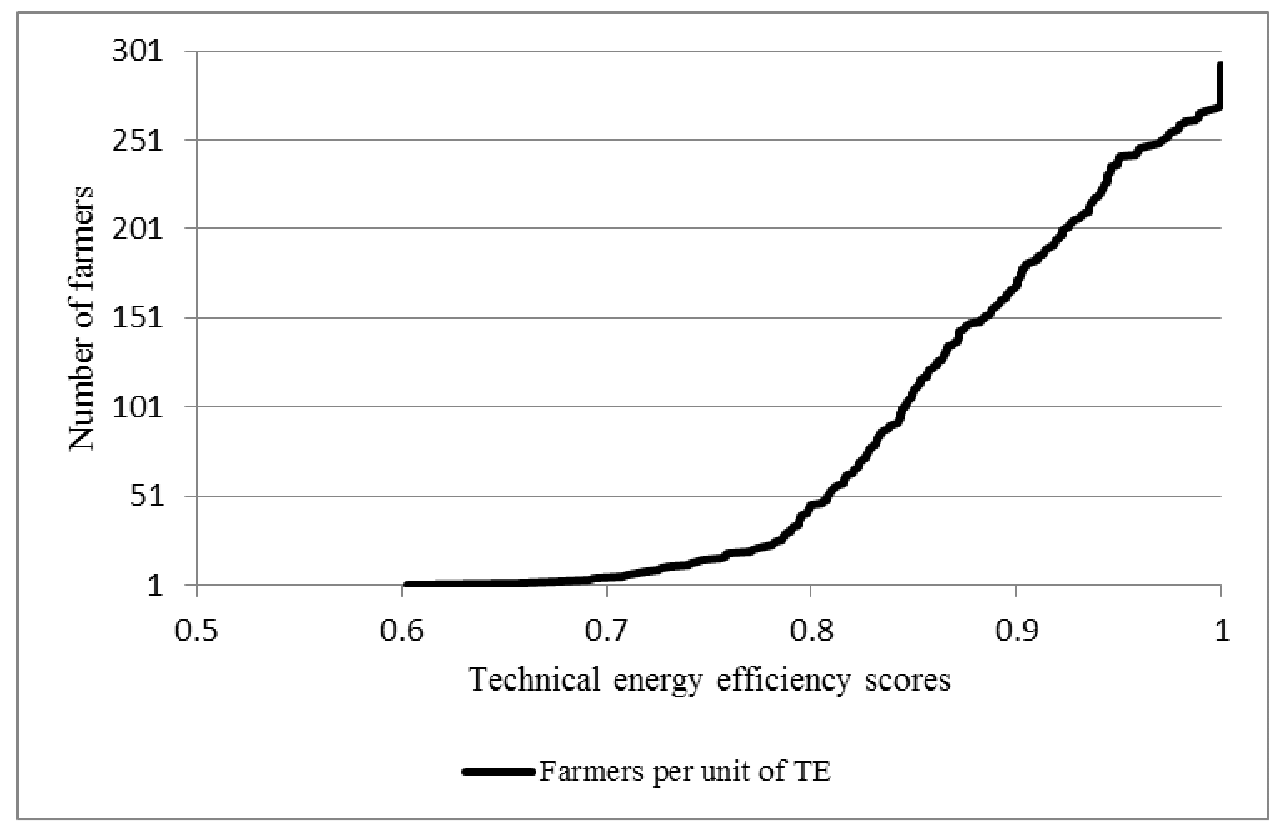

Figure 1. Technical energy efficiency distribution of wheat farmers in Bangladesh. 